limit the main cofactor of disease progression through well designed public health campaigns and interventions capable of reducing alcohol intake. In addition, measures should be taken to reach people in prisons and intravenous drug addicts, still at high risk for disease acquisition and spread. At the same time, researchers and epidemiologists should continue to study the clinical course of $\mathrm{HCV}$ infection in those countries where the disease is still actively spreading in the general population. ${ }^{12}$

\section{Sandro Vento associate professor}

(ventosandro@yahoo.it)

Section of Infectious Diseases, Department of Pathology, University of Verona, 37138 Verona, Italy

Valerio Nobili consultant physician

Department of Liver Diseases, Bambino Gesù Children's Hospital, 00100 Rome, Italy

Francesca Cainelli specialist in infectious diseases

Via Vasco de Gama 7, 37138 Verona, Italy

Competing interests: None declared.

1 Harris DR, Gonin R, Alter HJ, Wright EC, Buskell ZJ, Hollinger FB, et al. The relationship of acute transfusion-associated hepatitis to the development of cirrhosis in the presence of alcohol abuse. Ann Intern Med 2001;134:120-4.
2 Delarocque-Astagneau E, Roudot-Thoraval F, Campése C, Desenclos JC Past excessive alcohol consumption: a major determinant of severe liver disease among newly referred hepatitis $\mathrm{C}$ virus infected patients in hepatology reference centers, France, 2001. Ann Epidemiol 2005;15:551-7.

3 Wiese M, Grungreiff K, Guthoff W, Lafrenz M, Oesen U, Porst H, et al. Outcome in a hepatitis C (genotype 1b) single source outbreak in Germany-a 25-year multicenter study.J Hepatol 2005;43:590-8.

4 D’Souza R, Glynn MJ, Ushiro-Lumb I, Feakins R, Domizio P, Mears L, et al. Prevalence of hepatitis C-related cirrhosis in elderly Asian patients infected in childhood. Clin Gastroenterol Hepatol 2005:3:910-17.

5 Casiraghi MA, De Paschale M, Romanò L, Biffi R, Assi A, Binelli G, et al Long-term outcome (35 years) of hepatitis $\mathrm{C}$ after acquisition of infection Long-term outcome (35 years) of hepatitis $\mathrm{C}$ after acquisition of infection
through mini-transfusions of blood given at birth. Hepatology 2004;39:90-6.

6 Seeff LB, Miller RN, Rabkin CS, Buskell-Bales Z, Straley-Eason KD Smoak BL, et al. 45-year follow-up of hepatitis $\mathrm{C}$ virus infection in healthy young adults. Ann Intern Med 2000;132:105-11.

7 Ryder SD, Irving WL, Jones DA, Neal KR, Underwood JC. Progression of hepatic fibrosis in patients with hepatitis $\mathrm{C}$ : a prospective repeat liver biopsy study. Gut 2004;53:451-5.

8 Wali M, Harrison RF, Gow PJ, Mutimer D. Advancing donor liver age and rapid fibrosis progression following transplantation for hepatitis C. Gut 2002;51:248-52

9 Guadagnino V, Stroffolini T, Rapicetta M, Costantino A, Kondili LA, Menniti-Ippolito F, et al. Prevalence, risk factors and genotype distribution of hepatitis $\mathrm{C}$ virus infection in the general population: a community-based survey in Southern Italy. Hepatology 1997;26:1006-11.

10 Maio G, D'Argenio P, Stroffolini T, Bozza A, Sacco L, Tosti ME, et al. Hepatitis $C$ virus infection and alanine aminotran ferase levels in the Hepatit C vins infection and alanine aminotransferase levels in the general population: a survey in a southern Italian town. $J$ Hepatol

11 Global Burden of Hepatitis C Working Group. Global burden of disease (GBD) for hepatitis C.J Clin Pharmacol 2004;44:20-9.

12 Ahmad K. Pakistan: a cirrhotic state? Lancet 2004;364:1843-4

\title{
Surgery for emphysema
}

\section{New endoscopic techniques show promise}

$\mathrm{E}$ mphysema affects 3.1 million people in the United States alone and causes severe disability and early death in up to $45 \%$ of patients. ${ }^{1}$ Emphysematous destruction of the lung is associated with decreased elastic recoil pressure. As a result, the diseased lung requires less pressure than a normal lung to inflate and, once inflated, exerts less pressure to empty; lungs in emphysema therefore tend to remain inflated, with overexpansion of the rib cage and flattening of the diaphragm. Patients are trapped in a state of permanent hyperinflation and dyspnoea. No amount of effort can empty their lungs: the harder they strain to breathe, the more the airways collapse and obstruct the outflow of gas.

Current medical treatment with inhaled bronchodilators, glucocorticoids, mucolytics, and antioxidants may improve symptoms temporarily but does not prevent the decline in lung function. Various surgical procedures have been implemented in the past to relieve dyspnoea and improve quality of life for such patients. ${ }^{\mathrm{w} 1}$ Early results of surgery were often encouraging, but surgery rarely achieved sustained objective functional improvement and most of those procedures were gradually abandoned.

Bullectomy is the only operation that has stood the test of time. It allows re-expansion of restricted but potentially functional adjacent lung tissue, ${ }^{2}$ contributes to increased compliance and airway calibre, improves the ventilation-perfusion ratio $(\mathrm{V} / \mathrm{Q})$, and decreases the physiological dead space in the lung. Newer surgical procedures such as lung transplantation and lung volume reduction are now established procedures for selected patients, and endoscopic airway bypass and
International guidelines recommend lung transplantation as a viable option for a selected group of patients with end stage chronic obstructive pulmonary disease $(\mathrm{COPD})$-with forced expiratory volume $\left(\mathrm{FEV}_{1}\right)$ that is $25 \%$ lower than predicted, resting hypoxia, hypercapnia, secondary pulmonary hypertension, and a deteriorating clinical course. ${ }^{\mathrm{w} 2}$ Transplantation can produce excellent functional results and improve quality of life.w3 Patients with emphysema are ideal candidates for lung transplants because they experience a relatively slow functional deterioration and can tolerate a long wait for a suitable organ. They have enormous chest cavities, rarely suffer adhesions, and rarely have pulmonary hypertension. About 30\% of all lung transplants are done for patients with chronic obstructive pulmonary disease, ${ }^{\mathrm{w1}}$ and they have better postoperative outcomes than patients with other diseases such as pulmonary fibrosis or primary pulmonary hypertension., ${ }^{\text {w3 }}$

The choice of single versus bilateral transplantation in patients with emphysema remains controversial. Younger patients and those with giant bullae or bronchiectasis should be considered for bilateral transplantation to improve lung function and increase life expectancy and to avoid potential complications associated with having one remaining diseased lung. But bilateral transplantation reduces the potential for organ sharing and diminishes the already limited pool of donor organs. Moreover, chronic rejection due to obliterative bronchiolitis affects most patients within as little as five years after surgery, limiting long term survival substantially. ${ }^{3}$

References w1-w4 are on bmj.com 
An alternative to transplantation is lung volume reduction surgery. This reduces the size of the lungs and thereby can restore the lost circumferential pull on small airways, reduce hyperinflation, and can, on average, increase $\mathrm{FEV}_{1}$ by about $50 \%$ in most patients. ${ }^{4-8} \mathrm{w}_{4}$ The most destroyed areas of the lung, easily identified preoperatively by high resolution computed tomography and $\mathrm{V} / \mathrm{Q}$ scanning, are removed with linear staplers. This allows re-expansion and return to function of the adjacent more normal lung. But such surgery is only palliative and is associated with substantial morbidity; hence it is suitable only for selected patients needing temporary improvement in symptoms and quality of life. ${ }^{4-7}$ Only those patients with poor exercise capacity and with emphysema localised to the upper lobe survive longer after surgery than after medical treatment. ${ }^{8}$

The indications for lung volume reduction surgery and transplantation overlap considerably. Younger patients with clear contraindications to lung volume reduction (such as increased pulmonary artery pressure and hypercapnia) should undergo lung transplantation, while older patients and those with contraindications to transplantation should undergo volume reduction surgery. The choice should be taken on a case by case basis, after careful discussion with the patient, keeping in mind that volume reduction surgery could also be used as a bridge to lung transplantation.

There is preliminary evidence for minimally invasive surgery such as airway bypass and bronchoscopic lung volume reduction. Both techniques aim to improve respiratory mechanics through functional exclusion of emphysematous areas of the lung without exposing patients to the risks of a conventional operation.

Airway bypass aims to improve respiratory mechanics by creating new exit pathways for the air trapped in emphysematous lungs. Under bronchoscopic guidance the surgeon punctures the wall of the segmental bronchus and inserts a stent, thereby creating an internal bronchopulmonary communication for expiration. The aim is to reduce hyperinflation, improve respiratory mechanics, and alleviate dyspnoea. The procedure has been progressively modified to improve results and prolong the period of patency of the stents. The evidence for airway bypass is at an early stage though, comprising mainly an experimental model ${ }^{9}$ and a study of safety and efficacy in 15 patients having lobectomy for lung cancer or lung transplantation for emphysema. ${ }^{10}$

In bronchoscopic lung reduction surgery, one-way valves are placed in the segmental bronchi supplying the most hyperinflated parts of the emphysematous lung. Deflation and sometimes atelectasis of the target area prevent air entering from the target area of the lung while allowing air and mucus to exit. Pilot studies based on small case series show a functional improvement in selected groups of patients with heterogeneous emphysema, ${ }^{11}{ }^{12}$ and a prospective multicentre trial is comparing bronchoscopic lung volume reduction surgery with maximal medical treatment. Although the early evidence for bronchoscopic lung volume reduction is encouraging, it will take long term follow-up and randomised controlled studies to clarify the role of these interventions.

Federico Venuta associate professor of thoracic surgery (sofed@libero.it)

University of Rome "La Sapienza," Policlinico Umberto I, Department of Thoracic Surgery, Viale del Policlinico, Rome 00100, Italy

\section{Giulio Bognolo consultant cardiothoracic surgeon}

Cardiothoracic Unit, Barts and the London NHS Trust, London EC1A 7BE

Competing interests: FV participated in a pilot trial on the valve described in this editorial, where valves were provided free of charge from the company (Emphasys Medical, Redwood City, CA), which had no control over the conduct of the trial or the publication of the results. GB is an associate editor at the BMJ.

1 Anthonisen NR. Prognosis in chronic obstructive pulmonary disease: results from multicenter clinical trials. Am Rev Resp Dis 1989;140:595-9. De Giacomo T, Rendina EA, Venuta F, Moretti M, Mercadante E, Ibrahim De Giacomo T, Rendina EA, Venuta F, Moretti M, Mercadante E, Ibrahim
M, et al. Bullectomy is comparable to lung volume reduction in patients with end stage emphysema. Eur J Cardiothorac Surg 2002;22:357-62.

Heng D, Sharples LD, McNeil K, Stewart S, Wreighitt T, Wallwork J. Bronchiolitis obliterans syndrome: incidence, natural history, prognosis and risk factors.J Heart Lung Transplant 1998;17:1255-63.

4 Cooper JD, Trulock EP, Triantafillou AN, Patterson GA, Pohl MS, Deloney $\mathrm{PA}$, et Al. Bilateral pneumonectomy (volume reduction) for chronic obstructive pulmonary disease. J Thorac Cardiovasc Surg 1995;109: 106-19.

5 Ciccone AM, Meyers BF, Guthrie TJ, Davis GE, Yusem RD, Lefrak SS, et al. Long term outcome of bilateral lung volume reduction in 250 consecutive patients with emphysema. J Thorac Cardiovasc Surg 2003; 125:513-25.

6 Ramsey SD, Berry K, Etzioni R, Kaplan RM, Sullivan SD, Wood DE; NETT research group. Cost effectiveness of lung volume reduction surgery for patients with severe emphysema. $N$ Engl J Med 2003;348:2134-6.

7 Naunheim KS, Kaiser LR, Bavaria JE, Hazelrigg SR, Magee MJ, Landrenau RJ et al. Long term survival after thoracoscopic lung volume reduction: a multiistitutional study. Ann Thorac Surg 1999;68:2026-32

8 National emphysema treatment trial research group A randomized trial contial comparing lung volume reduction surgery with medical therapy for

9 Lausberg HF Chino K Patterson GA, Meyers BF, Toeniskotter PD, Cooper JD. Bronchial fenestration improves expiratory flow in emphysema human lungs. Ann Thorac Surg 2003;75:393-7.

10 Rendina EA, De Giacomo T, Venuta F, Coloni GF, Meyers BF, Patterson GA, et al. Feasibility and safety of the airway bypass procedure for patients with emphysema. J Thorac Cardiovasc Surg 2003;125:1294-9.

11 Toma TP, Hopkinson NS, Hiller J, Hansell DM, Morgan C, Goldstraw PC, et al. Bronchoscopic volume reduction with valve implants in patients with severe emphysema. Lancet 2003;361:931-3.

12 Venuta F, De Giacomo T, Rendina EA, Ciccone AM, Diso D, Perrone A, et al. Bronchoscopic volume reduction with one way valves in patients with heterogeneous emphysema. Ann Thorac Surg 2005;79:411-6.

\section{Liver transplantation from non-heart beating donors}

\section{A promising way to increase the supply of organs}

$\mathrm{S}$ ince its inception in the 1960s liver transplantation has seen such improvements in patient selection, surgical technique, perioperative care, and immunosuppression that it is now the treatment of choice for patients with liver failure. Indeed, like most other solid organ transplants, liver transplantation has become a victim of its own success with more patients now on the waiting list as the number of organ donors declines. Among the various approaches to increasing the number of donors, one of the most promising is the use of non-heart beating donors.

In general, liver donation rates are poor in the UK (13 per million population compared with 33 per million in Spain, the best in Europe; www.uktransplant. 